\title{
Article
}

\section{You don't see the world through the same eyes any more: The impact of sexual offence work on police staff}

Parkes, Ruth, Graham-Kevan, Nicola and Bryce, Joanne

Available at http://clok.uclan.ac.uk/25304/

Parkes, Ruth ORCID: 0000-0002-4491-4504, Graham-Kevan, Nicola ORCID: 0000-0003-0621-3093 and Bryce, Joanne ORCID: 0000-0001-9144-2899 (2019) You don't see the world through the same eyes any more: The impact of sexual offence work on police staff. The Police Journal, 92 (4). pp. 316-338. ISSN 0032-258X

It is advisable to refer to the publisher's version if you intend to cite from the work. http://dx.doi.org/10.1177/0032258X18812515

For more information about UCLan's research in this area go to http://www.uclan.ac.uk/researchgroups/ and search for <name of research Group>.

For information about Research generally at UCLan please go to http://www.uclan.ac.uk/research/

All outputs in CLoK are protected by Intellectual Property Rights law, including Copyright law. Copyright, IPR and Moral Rights for the works on this site are retained by the individual authors and/or other copyright owners. Terms and conditions for use of this material are defined in the policies page.

\section{CLoK}

Central Lancashire online Knowledge www.clok.uclan.ac.uk

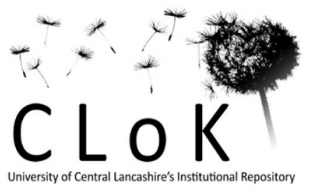




\begin{abstract}
This paper examines the experiences of Police staff in England who work with sexual offence material (SOM). Eleven officers completed a questionnaire then took part in semi-structured interviews. The data were analysed in two stages: Interpretative Phenomenological Analysis was used to illuminate the 'lived experience' of participants, and establish a theme structure. Clinical models of workplace trauma were then employed to explore the theme 'Impact of working with sexual offending'. Impact includes cognitive intrusions and increased suspiciousness. The authors identify where officers' accounts intersect with nascent symptoms of both Vicarious Traumatisation (McCann and Pearlman, 1990) and PostTraumatic Stress Disorder (PTSD).
\end{abstract}

Keywords: sexual offending material; police; PTSD; indecent images; interpretative phenomenological analysis 
Police officers and civilian Police staff investigating contact or online sexual offences are required to scrutinise a range of sexually explicit and potentially disturbing material on a regular basis. Sexual offence material (SOM) includes detailed examinations of forensic evidence, such as indecent images or videos of sexual abuse, along with written communication between people who derive sexual gratification from the abuse of children (Brady, 2016). In conjunction with this, Police staff are required to interview vulnerable victims and perpetrators in order to gather evidence about the offence. In both these interview settings, staff must seek to suspend their own personal feelings and reactions in order to maintain professional objectivity. This means, therefore, that they are required to manage their emotional and cognitive responses to having witnessed offences at the time they were perpetrated through indecent images, the aftermath of offences for the victim, and the offender's potential denial, minimisation or justification of their behaviour (Blagden, Winder, Gregson, \& Thorne, 2014; Burns, Bradshaw, Domene, \& Morley, 2008).

The proliferation of online indecent images of children (IIOC) in the last decade has been facilitated by the ubiquity of the internet, which has not only increased the accessibility of illegal images but has allowed like-minded offenders to find each other more easily and create online 'peer-to-peer' networks (Home Office, 2015). Sharing thousands of indecent images or producing a new image of abuse is often a pre-requisite to being allowed access to a particular online group (Krone, 2004; Wolak, Liberatore \& Levine, 2013). This encourages individuals to amass collections of images or commit their own contact offences in order to gain access to new material. In turn, repeated and extensive exposure to sexual abuse images has been found to result in habituation, leading to more extreme images being sought and collected (Aslan, Edelmann, Bray, \& Worrell, 2014; Wood, 2011). 
The increased volume and severity of images being produced and shared online and the concomitant increase in contact sexual offences has significant implications for those who are tasked with investigating such crimes. In the last 12 months that CAID (the Child Abuse Image Database) has allowed law enforcement agencies in England and Wales to make real progress in identifying victims and perpetrators at a pace which is ultimately hoped to match the rate of production of online sexual offence material (Home Office, 2015). The functions of CAID are similar to the Interpol International Child Exploitation Database of images (U.S. Department of Justice, 2016), assisting in the identification of 'known' child abuse images which have appeared on the computers of offenders in several cases. Once an individual image has been given the same severity categorisation by three different Police constabularies, it is considered a valid categorisation and is automatically sorted by CAID into the relevant category folder (Thomas, 2016). This reduces the volume of indecent images of children that officers have to view, leaving them free to sort through 'new' or first generation images depicting victims potentially known to the perpetrator in question. As well as increasing the speed with which cases can be processed, CAID offers the additional potential benefit of reducing staff exposure to traumatic material.

While the majority of exposure to SOM in Police constabularies in England and Wales is confined to those working in specialist sexual abuse teams or Public Protection Units (PPUs), any member of Police staff may encounter such material in the course of their duties. For example, a Neighbourhood Policing officer may be involved in the execution of a warrant concerning sexual offences and be exposed to SOM during a search of the premises. In other cases, the examination of a computer or phone for a drug related offence may unexpectedly uncover illegal sexual material. The level and type of interaction with sexually explicit evidence raises concerns about the potential for both short and longer-term negative consequences for those involved, such as hypervigilance or intrusive thoughts and images 
about the material (Perez, Jones, Englert, \& Sachau, 2010; Powell, Cassematis, Benson, Smallbone, \& Wortley, 2015). The World Health Organisation's ICD-10 (WHO, 1992) does not go into detail about the types of trauma which may precipitate PTSD, stating only that it can result from "acute severe stress or continued trauma". The DSM-V definition of PTSD crucially acknowledges that arousal and re-experiencing symptoms such as those outlined above can relate to those who experience 'repeated or extreme exposure to aversive details of the traumatic event' as part of their work, explicitly making reference to police staff repeatedly exposed to details of sexual abuse. The ICD 10 fails to recognise the potential long-term harm caused by repeated workplace exposure to traumatic stimuli, an omission also identified by MacEachern, Dennis, Jackson, \& Jindal-Snape in their 2018 study of UK Police officers working with traumatic incidents. The disparity between US and UK recognition of PTSD as a work-place issue perhaps reflects the historic lack of empirical research into the subject of work-related PTSD in the UK Criminal Justice System. The College of Policing's (2017) guidance on psychological risk management for UK Police chooses to reference the DSM-5 definition of PTSD rather than the ICD-10. This choice signals a recognition of the livedexperience and potential harmful outcomes of trauma exposure for UK Police officers and civilian staff, and this approach is mirrored within the current research.

Factors which may increase the likelihood of persistent negative symptoms following trauma exposure are described within Ehlers and Clark's (2000) Cognitive Model of PTSD. They suggest that susceptibility to ongoing traumatic stress symptoms is dependent on both the way in which the traumatic stimulus is perceived and how this is encoded in memory. Specifically, Ehlers and Clark propose that individuals have an increased vulnerability to PTSD if they display overly negative appraisals of both the trauma itself and their reaction to it, or if elaboration and integration of trauma information is limited. Negative appraisals may include the individual believing that they will never recover from the trauma, or that their 
reactions are abnormal. Poor integration may involve the person immediately and completely blocking any thoughts relating to the incident. Therefore, the way in which the trauma stimulus is encountered, the preparedness of the officer for exposure to sexual offence material, and the coping strategies used to manage exposure are key.

A high degree of engagement with sexual offence material (SOM) is required by Police officers and civilian staff in order to analyse its evidentiary value. This may include the close scrutiny of material in order to identify victims or perpetrators in indecent images, or categorise the severity of such images. To counteract such a high degree of immersion in a large volume of material, officers in the current study have been found to use coping strategies including detachment from the reality of the images and a process-driven approach where the material is dealt with mechanistically. Framed within Ehlers and Clark's (2000) Cognitive model of PTSD, these strategies would be described as 'blocking' techniques, a key risk factor for persistent traumatic stress symptoms.

Hochschild's (1983) concept of 'emotional labour' describes the process of presenting a certain outward impression in order to fulfil organisational expectations or 'display rules' for those working in the human services field. For Police staff interacting with victims or perpetrators of sexual offences during interviews, two choices may be available in terms of their reaction to the traumatic stimulus. They may engage in 'surface acting' by modifying their outward expressions to hide their true feelings such as anger, sadness or horror, or instead they may engage in 'deep acting', where the feelings themselves are modified by the officer changing the focus of their thoughts (Grandey, 2000). Surface acting in such prolonged and emotionally charged situations brings with it the experience of 'emotional dissonance'; a conflict between the felt and expressed emotions. By contrast, 'deep acting' utilises one of two strategies identified in Gross's (2015) Process Model of Emotional Regulation: 'attentional deployment', where the individual focuses on a less distressing 
aspect of the situation, or 'cognitive change' where the person changes their perspective about the situation as a whole. In the current context, this may include focusing on the endgoal of achieving justice for the victim. The cognitive load involved in conforming to display rules, and particularly in 'surface acting', has been linked to depletion of emotional and physical wellbeing (Hulsheger \& Shewe, 2011). This highlights the potential vulnerability of officers working with SOM to experience symptoms of 'Burnout' (Maslach, 1982) such as emotional exhaustion (Andela, Truchot, \& Van der Doef, 2016).

In the small but developing body of literature exploring the impact of exposure to sexual offending material on the psychological well-being of Police staff, the population of interest has thus far been largely the 'Internet crimes against children' task force staff (Bourke and Craun, 2014; Wolak and Mitchell, 2009; Brady, 2016) or Internet Child Exploitation (ICE) team members (Burns et al., 2008; Powell et al., 2014). No existing studies holistically explore the experiences of UK Police officers and civilian staff as a discrete group working with the full range of SOM. However, training and feelings of preparedness for working with online sexual offending were examined as part of a wider study into Police practice relating to online child safety across the UK, Ireland and the Netherlands. (Davidson et al., 2016).

There is growing evidence of unwanted psychological symptoms for Police staff linked to ongoing exposure to detailed information about sexual abuse. These include experiencing intrusions, namely unwanted thoughts and images about sexual offences (Powell et al., 2015); altered behaviour towards partners and children (Craun, Bourke and Coulson, 2015; Wolak and Mitchell, 2009), and changes to schema signalled by increased cynicism, suspiciousness and overprotectiveness (Burns et al., 2008; Perez et al., 2010). These results echo the findings of studies exploring the wider field of sexual offending work, such as those involving prison and probation staff or others delivering therapeutic 
interventions with perpetrators (Farrenkopf, 1992; Severson \& Pettus-Davis, 2013; Hatcher \& Noakes, 2010). Authentic accounts of the experiences of Police staff are particularly important to hear given the traditional expectation that officers appear invulnerable; a pressure which can come from both within the person themselves and from colleagues and superiors (Tuckey, Winwood \& Dollard, 2011). Clarke (2011) warns against pathologising workers' responses to sexual offence material, instead encouraging recognition of these responses as natural reactions to the burden of exploring the extremes of human depravity. This is an important consideration, and mirrors the importance of officers viewing their reactions to extreme material as 'normal', in order to reduce the risk of PTSD. However, in the current study, framing reactions within established constructs of psychological harm enables the identification of potential risks to the well-being of those who work with such material.

Knowledge about the nature and degree of threat posed by being routinely exposed to IIOC is still in its infancy (Powell et al, 2014; Brady, 2016). Therefore, the primary contribution of the current research is to extend the body of empirical data and deepen theoretical understanding of this phenomenon. This is achieved by exploring exposure to SOM in a range of contexts, including the potential long-term psychological impact of the work. There are inclusions in the DSM-5 (APA, 2013) definition of PTSD around those who may be repeatedly exposed to trauma through hearing or seeing the event indirectly through various media, with specific reference to sexual assault. Therefore this definition of PTSD can be seen to supersede other established terms such as 'Secondary Traumatic Stress' (Figley 1983), and 'Compassion Fatigue' (Figley, 1995 both in Figley, 2002), as the most appropriate term to define the potential adverse impact on Police of repeated exposure to sexual offence material. 
'Vicarious Traumatisation' (VT), (McCann and Pearlman, 1990) describes permanent alterations to schema as a result of exposure to the trauma of others. Despite some crossover with discrete PTSD symptoms, VT maintains an identity and relevance to the field of study distinct from PTSD. Affected areas of cognition are identified as safety, dependency/trust, power, esteem, intimacy, independence and frame of reference (about why events occur). Critics of VT as a construct would argue that there is insufficient empirical evidence to suggest that professionals exposed to others' trauma are 'significantly and adversely' affected (Kadambi \& Ennis, 2008). However, the internal working models identified within the theory of Vicarious Traumatisation have immediate resonance with disruptions to schema already identified within Police trauma literature, and are therefore worth further exploration in this context. The symptoms of PTSD under the DSM-5 will also be examined alongside participant responses within the current study. It should be noted that this is not intended to indicate a 'diagnosis' of PTSD but to explore the occurrence of individual symptoms within the sample.

In order to maintain a psychologically healthy and effective workforce, employers must recognise and have empathy for the mental effort required to cope with repeated exposure to traumatic sexual offence material. Hearing officers' authentic accounts of their experiences and exploring the links to established constructs of traumatic stress will develop this understanding, and help to inform the policies and practices underpinning staff support. The current study therefore explored the following questions:

1. Does repeated exposure to sexual offending material result in negative psychological consequences for Police staff?

2. What are the coping strategies employed by individuals in order to manage the impact, and are these adaptive or maladaptive? 
3. What is the relationship between general organisational stressors experienced by staff and specific stressors of sexual offending work?

4. What positives do staff derive from undertaking sexual offending work and how does this relate to the impact they experience and coping strategies they use?

\section{Method}

A complex interaction of personal, professional, organisational, social and cultural factors informs each person's unique responses to being exposed to sexual offending material. For this reason, a two stage interpretative model of analysis was used. Firstly, the principles of Interpretative Phenomenological Analysis (IPA) were used to gather the data and conduct the initial identification of themes. IPA allows the 'lived experience' of a small number of participants to be explored. This approach represents the converse of nomothetic psychological research, whose group-level results cannot offer specific detail about the actual participants who provided the data (Crotty, 1998). Ecological validity is essential; themes are allowed to develop without being fitted into a pre-existing format and the voices of participants are heard through direct use of quotes in reporting the results. Within IPA, transferability is explored through the demonstration of thematic patterns within participants' responses, using the specificity of these responses to search for common experiences across a wider sample in future studies. In the second phase of analysis, after identifying the theme 'Impact of the role', these data were subject to further interpretive study, by examining thematic links within definitions of clinical models of traumatic stress: Vicarious Traumatisation (VT) and Post-Traumatic Stress Disorder (PTSD). Ethical approval was obtained from the institutional ethics committee prior to data collection.

\section{Participants}


Participants comprised 11 individuals who work for an English Police constabulary. Teams which held potentially suitable participants (i.e. those who had contact with sexual offence material) were identified and contacted through the main project liaison, who held a senior operational management role. Staff members who indicated a willingness to participate completed a consent form, and consent was revisited immediately prior to the interviews. Following the interview, participants were provided with a debrief sheet detailing local and national sources of support.

All but one of the participants were working in a role that involved detailed involvement in sexual offending cases at the time of the study. The one participant who did not had previously worked in such a role for approximately five years. One participant was a civilian investigator and ten were Police detectives. Participants worked in a range of teams including a dedicated online child abuse team, Public Protection Units (PPU), and Criminal Investigation Division (CID) teams. Therefore the roles of the participants were heterogeneous. Six participants were female and five were male. Eight participants were parents and ten were in long term relationships, of relevance due to potential changes to relationships engendered by sexual offending work.

\section{Procedure}

\section{Open-ended questionnaire}

A questionnaire was created, with eight open-ended questions relating to the five elements of the overarching research question. These were: practitioners' general experiences of exposure to written, verbal and visual material relating to sexual offending; whether they had noticed any changes in terms of their thoughts, feelings or behaviour since doing the work; the strategies they used to help them to deal with exposure; what participants thought could be done to help them undertake their role; what the positive/motivating elements of the 
work were. Their responses formed the basis for the questions asked within the face to face semi-structured interview. As the interview questions expanded on all questionnaire responses the questionnaire data will not be reviewed separately here.

\section{Interviews}

The order of the interview questions was informed by a need to build sufficient rapport in a way which is mindful of the sensitive nature of the topic, and the importance of leaving participants on a positive note given the sensitivity of the subject matter (Smith, Flowers \& Larkin, 2009). This approach was informed by the lead researcher's professional expertise as a former Probation Officer, with over ten years' experience in interviewing individuals about sexual offending behaviour and personal circumstances during parole/pre-sentence report interviews. With this in mind, the interview schedule took the following format:

- Scene setting/procedural questions

- Questions about the impact of the work, coping strategies, support systems

- Questions about positives/motivation to do the work

The interview schedule was used as a prompt, and contained potential questions on the topics relevant to each participant. These were based on the research aims and the participant's answers within the questionnaire. The priorities and responses of the participant ultimately shaped the course of the interviews, and probing questions were used to explore the topics in greater depth. In order to gather the richest possible data relating to their experiences, participants were asked to recall incidents or cases which were particularly memorable. Questioning around a specific notable incident was recommended to the authors by Anke Ehlers, co-creator of the Cognitive Theory of PTSD (personal correspondence with authors, 2016).

\section{Data Analysis}


Interviews were audio recorded and transcribed verbatim by the lead researcher. The participant was sent the transcript and asked to verify that it was an accurate representation of the interview. This was also an opportunity for them to redact any information they did not want to be used in the research. The data was then subject to the stages of IPA outlined by Smith et al., (2009): Each interview transcript was read and re-read several times in order to identify salient themes, which were transferred to individual slips of paper to allow them to be manually arranged into theme clusters. This method allowed the author to physically group and re-group the themes in a variety of different ways until they started to form a coherent shape. Once the groups were settled upon, a table of themes and subthemes was drawn up. NVivo 11 was used to code and organise the structure of the themes. Every interview was analysed as a discrete entity, with no initial attempt to relate them to interviews that came before or afterwards in order to remain faithful to the individual's experience. Once this process was completed for all 11 participants, the superordinate themes, themes and subthemes were collated and transformed into a master-table to identify commonalties between participant responses. Once this process had taken place, the theme 'Impact of working within role' was subject to interpretative analysis by examining participants' responses alongside the constructs of Vicarious Traumatisation (McCann and Pearlman, 1990) and Post-Traumatic Stress Disorder (WHO, 1992; APA, 2013).

\section{Results}

The superordinate theme 'Impact of working within role' contained a number of themes and subthemes. One of the themes, 'Negative Impact' related to the immediate impact at the point of exposure to SOM: physiological and psychological responses such as revulsion or shock. However, the main focus of the current paper is on exploring negative impacts 
identified by participants as persistent over time, pervasive, or eliciting particular concern (see Table 1). These largely involve significant changes to the participants' view of the world, their relationships, or their control over their own responses. Results are presented using verbatim extracts from the interviews. Participants have been anonymised by the use of pseudonyms.

Table 1: Overarching themes relating to pervasive or persistent impact of exposure to SOM

- Becoming desensitised to sexual offence material.

- Personality change or significant ongoing impact.

- Behavioural/physical changes including irritability, moodiness \& sleep disruption.

- Cognitive changes including cynicism and suspiciousness of other people, or a negative general worldview.

- Intrusive images: unwanted, spontaneous recollection of either sexual abuse images viewed or self-generated images based on accounts of offences.

- Intrusive thoughts about the specific details of sexual offences or about concerns for victims.

- Indelible memories of cases

- Changes to interpersonal relationships such as lack of trust of own family members, disruption to sexual relationships.

- Increased self-consciousness or self-awareness when showing affection towards or playing with children, or undertaking normal parental tasks such as bathing.

- Changes to parental decisions such as allowing children to have access to technology or participate in social activities.

- Looking ahead with fear, dread, or trepidation 


\section{Desensitisation}

Where participants felt they were desensitised to sexual offending material through repetitious or intensive exposure, this was described as a natural consequence of their work. In most cases, the extent of desensitisation did not mean that the person felt nothing when exposed to material, but merely that for them, the 'shock factor' had diminished:

'Yeah, it's horrific what you're looking at, but you're not horrified by it. Does that make

$$
\text { sense? It's like... you just become numb' Anna }
$$

In only one case did the extent of desensitisation seem absolute:

'Unfortunately, indecent images of children don't really... have a reaction. Because... there's only so much you can do to a child and I've pretty much seen it all.' Paula

One participant seemed genuinely conflicted about the costs and benefits of desensitisation to Police staff who are required to work with sexual offending cases:

'Desensitisation's not saying 'Oh actually, I think it's alright'... Desensitisation is to the point you get where people think, it's... not normal, but they're not shocked by it any more. I think you have to be desensitised - a little bit - to do it. We have these things at work and people say 'Oh yeah, yeah, you can't be desensitised to it'. But then you go and spend eight hours looking at children being abused.' Jim

This highlights an inherent difficulty with managing repeated exposure to traumatic material: in order to preserve psychological health, participants in this study tried to distance themselves from what they were seeing and hearing by using a variety of coping strategies.

The most motivating factor for many staff in these roles is their desire to protect victims and the notion of achieving 'justice'. It could therefore be argued that strong emotions about the abhorrent nature of the material should remain intact while undertaking 
sexual offending work, in order to provide a sense of purpose. Total desensitisation runs the risk of dulling the feelings which underpin the individual's motivation to persist in their work, despite this requiring them to deal with such deeply disturbing material. Taking a taskcentred approach with the single-minded aim of achieving justice for victims may provide the answer to how an appropriate emotional balance can be achieved.

In contrast to the idea that repeated exposure automatically causes desensitisation, Burns et al (2008) suggest that instead, Police staff build up a mental repository of information about different acts of abuse, defined as 'stored knowledge'. This knowledge may cause staff to extrapolate or visualise more easily the harm being perpetrated outside of an individual image of abuse. Sandhu, Rose, Rostill-Brookes, and Thrift, (2011) found evidence of this in their study of therapists who provided treatment to sex offenders, stating 'the more you hear it, the more it goes in, the more you understand and the more it probably hurts you when you hear it' (Sandhu et al., 2011). The idea of 'stored knowledge' was borne out in the current study by a participant who experienced difficulties when dealing with a case where she has witnessed the same two girls growing up through a sequence of images of them being abused throughout their childhood.

'You know bad stuff happens in the world, but you can stop it happening again [for known victims]. But the children in the images... have been in that world and will continue to be in that world.' Nicole

For this officer, it was not only the images she was viewing that caused distress, it was imagining the suffering the victims were experiencing routinely as part of their lives. This indicates that rather than becoming desensitised, Police staff could actually become more sensitised to sexual offending material. In turn, this sensitisation feeds into the hypervigilance 
and arousal elements of PTSD, where anxiety levels about the risk of sexual abuse occurring are heightened, and danger anticipated even in benign circumstances.

\section{Personality change or significant ongoing impact}

Seven participants found that the cumulative effect of the work had at some time caused a significant reduction in well-being, including depression, anxiety, sadness or feelings of hopelessness. Such negative emotions are also typical symptoms of PTSD (WHO, 1992; APA, 2013). George described a case where he had been viewing a large number of indecent images, including first generation images of a local man raping his step-daughter. He said he had not been particularly affected by the images at the time, but vividly recalls being told about the outcome of an interview with the perpetrator by his supervisor some time later, which engendered a feeling of intense sadness. Nicole had profound feelings of powerlessness when viewing indecent images of children who were depicted having been abused over a number of years:

'It's happened, it may still be happening. But it could be anywhere in the world and there's no... well there's no fast way of finding that out and usually there's no way of finding it out at

$$
\text { all.' }
$$

Nicole's feelings of powerlessness reflect the findings of Speckens, Ehlers, Hackmann, Ruths and Clark (2007), who found that helplessness as an emotion is most commonly experienced during trauma exposure, while feelings such as sadness and anger tend to be encountered when re-experiencing the trauma at a later time through intrusive thoughts or rumination.

Feelings of helplessness were experienced by Police officers exposed to SOM in Burns et. al's 2015 study, while Iliffe and Steed (2000) found that professionals supporting victims of interpersonal violence felt 'inadequate, ineffectual and powerless' to prevent further harm. 
Identification of perpetrators and victims of on-line sexual offences - such as the production of indecent images - is uniquely problematic. Even when the catalyst for the investigative process is a victim coming forward, the perpetrator typically possesses illegal material involving multiple unknown victims as well. Priority is given to identifying victims in 'first generation' images, as resources in Police constabularies are insufficient to fully investigate the origin of the thousands of images that are commonly collected by perpetrators of this type of offence. Therefore, identification of the victims and perpetrators involved in the majority of images viewed within a case is by necessity a secondary consideration. The amount of abuse that is witnessed vicariously by Police staff and the practical impossibility of bringing all those responsible to justice is likely to impact upon their sense of control and self-efficacy, which in turn could lead to poor mental well-being including acute stress and depression (Asmundson and Stapleton, 2008). This may result in long-term absenteeism or staff leaving roles involving sexual offending, an issue which was identified by a number of participants as problematic within their workplace.

\section{Increased cynicism and suspicion}

Eight participants indicated they had become more suspicious about the behaviour or motives of others, or that their general worldview had become more cynical. This was identified as a general consequence of being a Police Officer: the job exposes them to aspects of human nature that are not necessarily visible to the general public. However, involvement with sexual offending work had often challenged and changed officers' views of the world in specific new ways. These beliefs had been altered in the participants as a consequence of being exposed to the darker drives and behaviours of human beings, which reach their apotheosis in the sexual abuse and torture of children. Suspiciousness and cynicism regarding 
people's intent to commit sexual offences had increased for some participants not just in terms of strangers and acquaintances, but in some cases their close family members:

'Even your own family... even your own parents, thinking 'is that level of tickling and fighting appropriate? Is that something that shouldn't happen?' And, you know, thought processes that, really, are not founded, and are ridiculous. But are there because of what you've been exposed to at work, what you've done.' Liam

Negative beliefs about others and a tendency to be extremely watchful or alert to others' behaviour are also symptoms of PTSD (WHO, 1992; APA, 2013). A belief in the inherent goodness of humanity is at risk of being irreparably damaged for those who spend a large proportion of their time immersed in the details of sexual offending. One participant's almost pathological fear of leaving her child with others meant that the only people she now trusted to do this were her own mother and her husband's mother. When it had been suggested that the child be left temporarily with the participant's step-father (who she had known since being a child herself), she was unable to do so, despite having no logical reason to distrust him. The question that presents itself is whether this kind of suspiciousness is in fact misplaced, or simply evidence of officers being aware that, overwhelmingly, sexual abuse is perpetrated by someone known to the victim (McAlinden, 2012):

I'm more cynical about the world generally and I've had my eyes opened to how many sex offenders there are. And also I suppose about the type of sex offences, that it's usually people you know, usually quite a close relative. It's not strangers that are gonna snatch a child off the street, that is so...disappearingly rare' Nicole The increased cynicism identified by participants was often linked to a theme uncovered during the analysis about Police staff being the 'Holder of Secret Knowledge', which describes the perception that they were the custodians of information about the horrors of the 
world that were hidden to the majority of people. This almost inevitably meant that their view of the world was seen through a more cynical lens than that of the general public. The theme of holding secret knowledge was encapsulated by one participant who reported that;

'You don't see the world through the same eyes any more, once you've done this job, this type

$$
\text { of work.' George }
$$

Six participants either felt isolated in social situations due to being unable to talk about work or, crucially, felt that by sharing their feelings they would 'contaminate' those close to them. In one case this was specifically related to preserving loved ones' innocence of certain facts that, for the officer, were simply a regular aspect of their work:

'I think you hide- it's like your Mum or your Dad asking you 'how was work' and, erm, you don't want to tell them, to shatter their-you know. It's to protect them, really. Because I think they would find it upsetting. What you have to deal with.' Katrina

When viewing the images taken from a suspect's computer or other digital storage system, not only are Police staff exposed to images of sexual abuse of children and other vulnerable people, but also images depicting bestiality, torture, and mutilation. For some participants, these images were just as disturbing as indecent images of children, and served to demonstrate the variety of ways in which human depravity can manifest itself. With intense and repeated exposure to such material on a regular basis, it is unsurprising that they sometimes struggled to view the world as a benign place. In order to guard against despair and recalibrate their view of the world, some participants were able to employ a coping strategy where they stepped back and looked at their work in the context of their broader lives, finding a sense of perspective. It is perhaps those who are unable to find this sense of perspective who experience more problematic and enduring negative consequences, as they may struggle to see the good in the world or in other people. 


\section{Intrusive thoughts and images}

Nine participants had intrusive thoughts about work, some of which related to worrying about victims, prioritisation of workload or other general work stressors. In a number of cases there were specific references to experiencing intrusive images of the sexual material they have seen or heard. Certain factors made this more likely to happen, such as having to spend extended periods of time viewing indecent images, viewing images multiple times for the purposes of preparing evidence for Court, or where the victim or circumstances of the offence had resonance with the person's own life. For George, all three of these factors coalesced in one case which caused him particular difficulty, where he had to watch a video of a child being raped:

'I know what the link was... Basically it was sort of the shoulders downwards, torso of a child. It was a child the same age as my daughter. I mean I must have watched it about 20 times, and that did get to me. But it was because the child was a similar age to my daughter. It was the same bodily characteristics as my daughter at the time.'

For this participant, the repetition of exposure and the victim characteristics meant that he mentally visualised the abuse happening to his own child. One participant described how she can still see the images scrolling through her mind as if she was still viewing them on a computer screen. Others talked about the persistence of memories of certain cases over time:

'And that was the hardest thing to switch off from. That was...terribly difficult to get out of your head for a day or two... and then of course, you have flashbacks to it. And just sat here talking now, you 're remembering bits of it.' Martin

Jasmine described her inability to control the events that followed the disclosure of intra-familial abuse by a victim. Despite acting in the victim's best interests by preventing 
further abuse, she was horrified that the criminal justice process led to the victim having no further contact with her family and being subjected to chaotic experiences within the care system. When discussing this, Jasmine recalled the case so vividly that it resulted in a level of distress that she found difficult to regulate for an extended portion of the interview. This illustrates the pervasive nature of the impact of working with SOM. Negative emotions can overwhelm the individual not only during direct exposure or while the case is ongoing, but when recalling or recounting the experience months or even years later. This type of ongoing impact is also a symptom of PTSD (WHO 1992; APA, 2013).

\section{Indelible memories of cases}

As well as experiencing fleeting intrusive thoughts and images, participants gave accounts of cases or individual images that they felt they would never forget. The indelible nature of these images was sometimes linked to the similarity of the victim to someone they knew. In other cases, it was linked to whether or not the participant had met the victim, for example when they had viewed indecent images of children then interviewed the child in question, or vice versa. For many, this was much harder than seeing images of victims they did not know:

'I think it's harder because I... I can't, you can't switch off that kind of empathy. You've spoken to them, and you've had to do things that you would do with your own children; sit down, colour with them, you're talking about things in their room... So already within your mind's eye, you have a mental image of who this child is, what their interests are and things.

So if you're then having to view images that involve them, you can't just switch off that empathy...to think that's just another image. You've kind of, already got an idea of them, and 
you're then starting to think about how what has happened to them would have affected them.

\section{And how they felt at that moment in time.' Liam}

Police staff are in a unique and unenviable position compared to other professionals who are required to deal with sexual trauma: they deal not only with primary evidence of offences and interview the perpetrators of sexual harm, but are also exposed to the aftermath of the abuse when speaking to the victims.

\section{Hiding negative impact}

Despite the significant impact several participants described, they equally felt that they had to hide any sign that they were having difficulty with the work, due to an expectation either emanating from within themselves or from supervisors that they should be able to cope:

'We've chose to, to do this job, you see. I've chosen to be a Police Officer, so it's that expectation that you've got to...crack on, really.' Katrina

'You don't want to be looked at... as like you're not coping. And I think a lot of people are scared ... to say actually, enough's enough.' Anna

It is clear that cultural expectations still persist for staff in terms of a perception that Police officers should be or appear to be infallible. This was linked in the current study to notions of 'failure' and 'weakness', with participants not wanting to be seen by colleagues or superiors as unreliable.

\section{Changes to interpersonal relationships and increased self-consciousness}


Some participants commented that they did not feel their relationships with family or friends had changed at all. However, more than half gave examples of how their thoughts or behaviours within relationships had changed. Two of these people cited decreased libido or avoiding sexual contact with their partner to avoid triggers to thinking about sexual offence material. Six people mentioned an emotional or cognitive toll on home life and relationships, such as being distracted, being unable to 'switch off', choosing to isolate themselves, or becoming snappy or moody. Another facet to the change in interpersonal relationships was increased self-consciousness about everyday parental situations. This seemed to generate frustration around the contamination of their thought processes while spending time with their children. It seems that knowledge about sexual offending and the ways in which perpetrators facilitate the abuse of children cannot simply be confined to the work setting:

I personally was ultra-conscious of then thinking about how these offenders had kind of... moved from perhaps being a parent, into offending, through their own parenting style. Those kind of thought processes that you're working through, then encroach into your... you start to perhaps put stricter barriers in your own life. Should we be cuddling in bed now? Should I be bathing the girls? Should, should my wife be bathing the girls?' Liam

Nicole discussed how blowing raspberries on her children's stomachs now reminded her of an indecent image she had viewed where the perpetrator had done this as a pre-cursor to abuse:

'I wouldn't necessarily do that very often anyway, but now I think, well, shouldn't I do it? Or should I do it? And...it shouldn't even be a thought-out process, it should be, you know, something that you're just, you're just playing with your kids...even though you try not to let it, you have that thought process. Even though your actions might not change, you've got that thought process of whether you should or you shouldn' $t$ ' 
The conditioning evident in the above example, in this case where an innocuous stimulus (blowing a raspberry) is paired with a guilt response, indicates the insidious way in which aspects of sexual offence material can enter the consciousness of professionals and lead to them questioning their own innocent behaviour.

\section{Changes to parental decisions}

Six of the eight participants who were parents described changes to their decisions or thought processes about things such as allowing their children to go on sleepovers, or the extent to which they are allowed access to technology and social media. In some cases, the changes to parental decisions are directly linked to a lack of trust in other people's motives, and persist even when the individual is aware that their response may be extreme:

'I wouldn't just let them just have a sleepover at anybody's house... and even ... like going for tea, and stuff like that. [Long pause] When you say, when you say it out loud, [laughing] it just sounds so ridiculous! That, that I wouldn't allow cer-certain things like that to happen.

But I don't trust people. I really don't. And that, that's what it boils down to. That trust.'

\section{Anna}

The changes to parental decisions identified by participants illustrate alterations to schema relating to the safety of the world and the trustworthiness of others.

\section{Looking ahead with fear, dread, trepidation}

Five participants articulated negative anticipatory feelings which could be characterised as dread when thinking about having to do more sexual offending work. In some cases, this was a fear of the unknown about what the work will entail, and in other cases 
concerns related particularly to how they might cope when faced with SOM. It is interesting that fear of their own reactions is as much a concern to some individuals as concerns about the material itself.

For these individuals, the chances of developing traumatic stress symptoms may be linked to their perception of their own ability to cope: Ehlers and Clark's Cognitive theory of PTSD (2000) holds that if an individual perceives themselves as a person who always copes well, the emergence of symptoms such as tearfulness, anxiousness or intrusive memories as a result of trauma may be experienced as especially concerning and abhorrent. This has implications for staff support, in terms of recognising the personality characteristics which may make an individual more susceptible to developing symptoms associated with PTSD as a result of repeated exposure to sexual offending.

\section{Discussion}

The overarching aim of the current study was to better understand the lived experiences of individual Police officers and civilian Police staff who are required to analyse material relating to sexual offences. Within this broad aim, the study was designed to provide an insight into the challenges of the work and the human cost in terms of psychological impact. This paper has focused specifically on cognitive, behavioural and affective changes, ranging from desensitisation to hypervigilance and changes to relationships with others. The findings mirror those identified within research concerning the experience of Police officers working with child homicides (Roach, Cartwright, \& Sharratt, 2017), and staff working in Family Protection Units (FPUs) (MacEachern, Dennis, Jackson, \& Jindal-Snape, 2018). Psychological symptoms included sleeplessness, rumination, increased tearfulness and disruptions to interpersonal relationships. 


\section{Effects on worldview and schema}

The seven areas of schema affected by repeated indirect exposure to the trauma of others in McCann and Pearlman's 'Vicarious Traumatisation' model (1990) are: Safety, dependency/trust, power, esteem, intimacy, independence and frame of reference. A number of salient illustrations in the current data show the presence of the first five types of alteration to people's internal working models. For example, the element of 'Dependency/Trust' and the level of 'Esteem' in which others are held relate closely to the theme 'increased cynicism and suspicion'. 'Intimacy' was found to be disrupted both in terms of changes to or selfconsciousness about interpersonal relationships, and the distancing of participants from their loved ones caused by an inability to discuss their working life. However, no distinct relevance was found within the data for the concepts of 'independence' as a separate entity from 'safety', nor was there evidence of disruption to 'frame of reference' as to why events occur. The initial analysis shows that Vicarious Traumatisation, a concept originally coined to describe traumatic stress experienced by those working therapeutically with victims, may only be partially applicable to a Police sample. Further exploration is desirable however, and will be examined in future strands of the current programme of study.

Participants' reactions provide evidence to support Epstein's (1991) thesis that trauma can fundamentally disrupt four elements of people's worldview: that the world is benign; that it is 'meaningful, predictable, controllable and just'; belief in the inherent trustworthiness of others; belief in the worthiness of themselves as individuals. The most significant type of impact resulting from exposure to sexual offending material is the pervasive nature of the changes to worldview and behaviour. These changes are echoed across the literature both in terms of Police staff and people working therapeutically with victims or perpetrators of 
sexual abuse and include: Self-consciousness about their own behaviour around children (Bengis, 1997); avoiding sexual contact (Ellerby, 1997); suspiciousness of others' behaviour, (Nen, et al., 2011); over-protectiveness of own children (Shelby, Stoddart, and Taylor, 2001), and general cynicism (Iliffe \& Steed, 2000).

\section{Effects mirroring PTSD symptoms}

There is evidence to suggest that re-experiencing is a common occurrence for Police staff exposed to sexual offence material (Bourke \& Craun, 2014; Powell et al., 2014), coded within the current study as 'Intrusive thoughts' and 'Intrusive Images'. Even discounting the comments about intrusions which could relate to all aspects of Police work, such as ruminating about how to prioritise tasks, a substantial number of 're-experiencing' accounts remain. One of the subthemes within this area of impact is thoughts or images about offences occurring at random times, or when showing affection towards children or partners. The disconcerting juxtaposition of thoughts and images of sexual abuse within a domestic or sexual context have the potential to cause cognitive dissonance and a change to relationship intimacy (Bengis, 1997; Freeman-Longo, 1997). This phenomenon would therefore benefit from further exploration.

Intrusions are linked to a sense of self-control, with some officers seeing images 'all the time', being unable to 'switch off' from them or seeing them scrolling through their mind after viewing indecent images for an extended period of time. When seeing or thinking about SOM is not confined to the actual physical exposure but is repeated unbidden against the backdrop of their private thoughts, practitioners may feel they are not fully in control of their own minds. Certainly some participants in the current study felt that memories of things they had witnessed were indelible and that they were powerless to forget them. 
Avoidance of triggers that would serve as reminders of sexual offences is a symptom of PTSD also evidenced within the current study. This largely relates to the theme 'Changes to interpersonal relationships' and 'Increased self-consciousness', where participants have avoided sexual contact with their partner or avoided certain behaviours towards their children which act as reminders of sexual offences. As well as the many subthemes which describe negative feelings at the point of exposure to SOM such as frustration, horror and sadness, concepts indicating longer term impacts such as being desensitised, contaminated or isolated from others were also well supported by the data. Perhaps most importantly, the primary coping mechanisms by which participants in the current study dealt with direct exposure to the work all involved aspects of emotional numbing. Avoidance of emotional triggers by limiting engagement with the material, detachment from the reality of the material or from the victim through emotional distancing or suppression, or focusing purely on the process rather than the content (thereby separating the logical and emotional selves) were used in varying combinations by all participants.

\section{Coping strategies and motivation as mediating factors}

One of the key factors relevant to the nature and extent of the negative impact experienced by Police staff was the implementation of one of the three coping strategies emerging from the data: Detachment-based strategies, Avoidance-based strategies and Process-driven strategies, which are mirrored within other studies of professionals who work with sexual offence material (Burns et al., 2008; Powell et al., 2010). Limitations to the effectiveness of coping techniques has direct relevance for the severity of the impact of the trauma exposure. This includes the difficulty staff experience in detaching from the material or adopting a purely process driven approach when having to look at indecent images of 
children who they have already spoken to during interviews. Staff may therefore be at greater risk of negative psychological impact if they are required to both interview victims and view indecent images, as this may nullify their usual coping responses. Perspective-taking exercises within dedicated supervision or de-briefing sessions would therefore be a useful part of staff well-being support, as the material and responses to it could be contextualised. This would fit into a broader programme of mindfulness training designed to avoid rumination, and therefore control feelings of stress and anxiety (McKenzie \& Hassed, 2015).

A range of motivations to undertake the work were identified by participants in the current study, who all articulated a powerful desire to protect vulnerable victims and achieve justice for them. The vocational drive or 'Compassion satisfaction' (Figley, 2002) held by those working with traumatised people has been found to be protective against any negative impact of the work becoming overwhelming (Brady, 2016; Kadambi \& Truscott, 2006; Hatcher \& Noakes, 2010). Therefore ongoing support of staff should include a motivational element where personal successes and positive outcomes to cases are a permanent item on the supervision agenda.

\section{Expectations about coping}

The concept of 'Emotional Labour' states that for each profession, there are certain 'display rules' which must be followed (Hochschild, 1983). In the current study, there were several statements about the pressure to appear invulnerable, including the need to subsume thoughts and feelings about being unable to cope. The literature on Police culture confirms that, despite some progress in breaking down the perception that staff must portray stereotypically masculine traits such as a lack of emotionality, this culture still persists (Loftus, 2009; Rumens \& Broomfield, 2012). In the current study, participants indicated a 
reluctance to seek support when they were struggling to cope or were experiencing negative consequences as a result of their work. This related both to a fear of being seen as not coping by superiors and peers, and internal pressure to manage their responses to the work in order to avoid feeling they had 'failed' in fulfilling their role. Although some participants did feel able to seek help, others formed the opinion that they should be able to cope with anything as a Police officer, failing to see themselves as worthy of support until they had reached breaking point.

An individual's appraisal of not only the trauma itself but of their own reactions to the trauma are central to Ehlers \& Clark's Cognitive Theory of PTSD (2000), who posit that those who struggle to see their reactions as 'normal' are more at risk of developing PTSD. In the current sample, there was evidence that for some participants, struggling to cope with a particular case equated to fundamental personal or professional failings on their part. Given the strong theme that emerged regarding an organisational culture where staff were expected to 'get on with it', it would be reasonable to suggest that this may feed into staff perceptions that needing help is not 'normal'. As well as acting as a barrier to seeking help, these perceptions may actually place them at greater risk of developing PTSD symptoms.

According to the Cognitive Theory of PTSD (Ehlers and Clark, 2000), feeling their reactions are abnormal is also likely to encourage staff to use 'blocking' coping strategies which tend to increase the likelihood of unwanted intrusions. This signals the importance of an attentional shift by Police organisations towards recognising and normalising the idea that working with sexual offending material is highly unpleasant and therefore has the potential to cause distress or other unwanted consequences. Protecting staff from psychological harm will therefore require a supervision model where well-being issues can be openly identified and discussed. Staff can then be supported by means of sensitive workload allocation, ongoing training both in self-care and operational techniques, and by signposting to organisational and 
external support systems. Based on the comments made by participants in the current study, the key elements of these supports are that they should be available at point of need, confidential, and trusted by staff. This latter point means that those providing support must have a practical understanding of the challenging nature of sexual offending work. Powell et el., (2014) found that criminal justice professionals working with sexual offending were often reluctant to make use of organisation psychological support services due to the therapist being underqualified and indeed reluctant to hear details about sexual offending. Clinical supervision has been found to reduce self-reported difficulty with the work and traumatic stress symptoms (Bourke and Craun, 2014; Burns et al., 2008) and should be an in-built element of the role, to avoid being perceived as a stigmatising and therefore unpopular 'optin' measure.

\section{Strengths and Limitations of the current study}

As a small scale qualitative study, the current findings are not, nor were they intended to be, generalizable to the wider population of Police staff who examine sexual offence material. Although participants varied in age, relationship status, parental status, gender, role, and length of time working with sexual offences, there is no way of knowing whether their views were representative of the broader staff group. However, identification of meaningful themes authentic to the experiences of Police staff was made possible through Interpretative Phenomenological Analysis in the first phase of analysis. This has facilitated a deeper understanding of the experiences of the 11 individuals involved in the study in a way that values their unique perspectives. The researcher then interprets participants' responses based on their own understanding of what has been said (Smith et al., 2010). Therein lie both the benefits and risks of the researcher having pre-existing knowledge of the topic of study. Their 
cultural capital means that the implications of responses are better understood within the professional and organisational context, but this 'insider status' (Drake and Heath, 2011) may mean the researcher is susceptible to foregrounding their own experiences. The authors do not attempt to clinically diagnose PTSD in participants; instead they explore the occurrence of individual symptoms identified by the sample. Future studies may wish to explore exposure to sexual offence material from a medico-psychological rather than experiential perspective.

The richness of the data has provided much needed insight into the challenges that Police staff face in working with sexual offence cases. Themes identified by participants have been used as the basis for survey questions which are being currently being tested on a larger sample of staff from the same constabulary. Data from this survey will be further analysed to determine the transferability of the themes to others within the target population. This includes an exploration of the experiences of staff not only in specialist sexual offending roles but any officer or staff member who may be exposed to SOM, including civilian typists and neighbourhood officers. Effects linked to the frequency, duration, and longevity of exposure to SOM will also be examined.

\section{Conclusion}

This paper has reported on a qualitative analysis of the experiences of Police staff who work with sexual offence material, focusing on one of largest overarching themes; the impact that the role has had on their wellbeing. The participants involved showed varying levels of negative impact as a result of working with SOM, and many had strong motivations which 
enabled them to continue to find meaning in the work. Some exhibited a number of symptoms to suggest that they may be at risk of PTSD, as well as compelling evidence that several of their underlying beliefs and perspectives about the world and about other people had been irrevocably altered as a result of their work. There is evidence in some cases that their internal working models about themselves had been disrupted, with participants questioning their own behaviour and thoughts. Some questioned their professional efficacy when struggling with aspects of sexual offending work, as though they should not feel or show the human emotions that are naturally engendered by this most challenging of tasks. There are clear links to an organisational Police culture which still struggles to accept expressions of distress as a normal response to abnormally frequent and severe exposure to traumatic incidents. Further work exploring the experiences of a broader range of Police staff members who deal with sexual offending cases is currently underway. The larger number of participants involved will allow for a more detailed exploration of the impact of the work, and its relationship to permanent alterations to worldview and PTSD. This data will be used to make further recommendations for the selection, training and support of staff.

\section{References}

American Psychiatric Association. (2013). Diagnostic and statistical manual of mental disorders (5th ed.). Arlington, VA: American Psychiatric Publishing. 
Andela, M., Truchot, D., \& Van der Doef, M., (2016). Job stressors and burnout in hospitals: The mediating role of emotional dissonance. International Journal of Stress Management, 23(3), 298-317. doi:10.1037/str0000013

Aslan, D., Edelmann, R., Bray, D., \& Worrell, M. (2014). Entering the world of sex offenders: An exploration of offending behaviour patterns of those with both internet and contact sex offences against children. Journal of Forensic Practice, 16(2), 110-126. doi:10.1108/JFP-02-2013-0015

Asmundson, G. J. G., \& Stapleton, J. A. (2008). Associations between dimensions of anxiety sensitivity and PTSD symptom clusters in active-duty police officers. Cognitive Behaviour Therapy, 37(2), 66-75. doi:10.1080/16506070801969005

Bengis, S. (1997). Personal and interpersonal issues for staff working with sexually abusive youth. In S. Bird Edmunds (Ed.), Impact: Working with sexual abusers (pp. 31-50). Brandon, Vt: Safer Society Press.

Blagden, N., Winder, B., Gregson, M., \& Thorne K. (2014). Making sense of denial in sexual offenders. Journal of Interpersonal Violence 29(9), 1698-1731.

Bourke, M. L., \& Craun, S. W. (2014). Secondary traumatic stress among internet crimes against children task force personnel: Impact, risk factors, and coping strategies. Sexual Abuse: Journal of Research and Treatment, 26(6), 586-609. doi: $10.1177 / 1079063213509411$

Bourke, M. L., \& Craun, S. W. (2014). Coping with secondary traumatic stress: Differences between U.K. and U.S. child exploitation personnel. Traumatology: An International Journal, 20(1), 57-64. doi:10.1037/h0099381 
Brady, P. Q. (2016). Crimes against caring: Exploring the risk of secondary traumatic stress, burnout, and compassion satisfaction among child exploitation investigators. Journal of Police and Criminal Psychology, 31(4), 1-14. doi:10.1007/s11896-016-9223-8

Burns, C. M., Morley, J., Bradshaw, R., \& Domene, J. (2008). The emotional impact on and coping strategies employed by police teams investigating internet child exploitation. Traumatology, 14(2), 20-31. doi:10.1177/1534765608319082

Chassman, L., Kottler, J., \& Madison, J. (2010). An exploration of counselor experiences of adolescents with sexual behavior problems. Journal of Counseling \& Development, 88(3), 269-276.

Clarke, J. (2011). Working with sex offenders: Best practice in enhancing practitioner resilience. Journal of Sexual Aggression, 17(3), 335-355. doi:10.1080/13552600.2011.583781

College of Policing. (2017). Psychological risk management. UK. College of Policing

Craun, S., Bourke, M., \& Coulson, F. (2015). The impact of internet crimes against children work on relationships with families and friends: An exploratory study. Journal of Family Violence, 30(3), 393-402. doi:10.1007/s10896-015-9680-3

Crotty, M. (1998). The foundations of social research: Meaning and perspective in the research process. London, UK: Sage publishing.

Davidson, J., DeMarco, J., Bifulco, A., Bogaerts, S., Caretti, V., Aiken, M., Cheevers, C., Corbari, E., Scally, M., Schilder, J., Schimmenti, A., \& Puccia, A. (n.d.). Enhancing police and industry practice: EU child online safety project. Retrieved from http://www.mdx.ac.uk/_data/assets/pdf_file/0017/250163/ISEC-report-FINAL.pdf 
Drake, P., \& Heath, L. (2011). Practitioner research at doctoral level: Developing coherent research methodologies. Abingdon, UK: Routledge.

Ehlers, A., \& Clark, D. (2000). A cognitive model of posttraumatic stress disorder. Behaviour Research and Therapy, 38(4), 319-345.

Ellerby, L. (1997). Impact on clinicians: Stressors and providers of sex-offender treatment. In S. Bird-Edmunds (Ed.), Impact: Working with sexual abusers (pp. 51-60). Brandon, Vt: Safer Society Press.

Epstein, S. (1991). Cognitive-experiential self-theory: An integrative theory of personality. In R. C. Curtis (Ed.), The relational self: Theoretical convergences in psychoanalysis and social psychology (pp. 111-137). New York, NY: Guilford Press.

Farrenkopf, T. (1992). What happens to therapists who work with sex offenders? Offender Rehabilitation, 18 (3/4). 217-224.

Figley, CR (1995) Compassion fatigue as secondary traumatic stress disorder: An overview. In Figley, CR (ed) (pp. 1-20). Philadelphia, PA, US: Brunner/Mazel. Retrieved from http://search.ebscohost.com/login.aspx?direct=true\&db=psyh\&AN=1995-97891$\underline{001 \& \text { site }=\text { eds-live }}$

Freeman-Longo, R. E. (1997). A personal and professional perspective on burnout. In S. Bird Edmunds (Ed.), Impact: Working with sexual abusers (pp. 5-9). Brandon, Vt: Safer Society Press.

Grandey, A. A. (2000). Emotional regulation in the workplace: A new way to conceptualize emotional labor. Journal of Occupational Health Psychology, 5(1), 95-110. doi:10.1037/1076-8998.5.1.95 
YOU DON'T SEE THE WORLD THROUGH THE SAME EYES

Gross, J. J. (2015). Emotion regulation: Current status and future prospects. Psychological Enquiry, 26, 1-26.

Hatcher, R., \& Noakes, S. (2010). Working with sex offenders: The impact on Australian treatment providers. Psychology, Crime \& Law, 16(1-2), 145-167. doi:10.1080/10683160802622030

Hochschild, A., (1983). The Managed Heart. Berkeley, Ca: University of California Press Home office. (2015). Child Abuse Image Database. Retrieved from https://www.gov.uk/government/uploads/system/uploads/attachment_data/file/478006/4817

\section{CAID_Booklet_v13_online4.pdf}

Hülsheger, U. R., \& Schewe, A. F. (2011). On the costs and benefits of emotional labor: A meta-analysis of three decades of research. Journal of Occupational Health Psychology, 16(3), 361-389. doi:10.1037/a0022876

Iliffe, G., \& Steed, L. (2000). Exploring the counselor's experience of working with perpetrators and survivors of domestic violence. Journal of Interpersonal Violence 15(4), 393-412.

Kadambi, M., \& Ennis, L. (2008). Reconsidering vicarious trauma. Journal of Trauma Practice, 3(2), 1-21.

Kadambi, M., \& Truscott, D. (2006). Concept mapping professionals' perceptions of reward and motive in providing sex offender treatment. Journal of Offender Rehabilitation, 42(4), 37-58. doi:10.1300/J076v42n04-03

Krone, T. (2004). A typology of online child sexual offending. Trends and Issues in Crime and Criminal Justice. 279, 261-280. 
Loftus, B. (2010). Police occupational culture: Classic themes, altered times. Policing \& Society, 20(1), 1-20. doi:10.1080/10439460903281547

McAlinden, A. (2012). 'Grooming' and the sexual abuse of children: Institutional, internet, and familial dimensions. Oxford, UK: Oxford University Press.

McCann, I. L., \& Pearlman, L. A. (1990). Vicarious traumatization: A framework for understanding the psychological effects of working with victims. Journal of Traumatic Stress, 3(1), 131-149. doi:10.1007/BF00975140

MacEachern, A., Dennis, A., Jackson, S., \& Jindal-Snape, D. (2018). Secondary traumatic stress: Prevalence and symptomology amongst detective officers investigating child protection cases. Journal of Police and Criminal Psychology, 1-10. doi:10.1007/s11896018-9277-x

McKenzie, S., \& Hassed, C. (2015). Mindfulness for life. Auckland, Australia: Exisle Publishing.

Meichenbaum, D. (2007). Stress inoculation training: A preventative and treatment approach. Principles and practice of stress management, 3, 497-518.

Nen, S., Astbury, J., Subhi, N., Alavi, K., Lukman, Z., Sarnon, N., Fauziah, I., Hoesni, S., \& Mohamed, M. (2011). 'The impact of vicarious trauma on professionals involved in child sexual abuse cases.' Journal of Social Sciences and Humanities, 19, 147-155.

Perez, L., Jones, J., Englert, D. R., \& Sachau, D. (2010). Secondary traumatic stress and burnout amongst law enforcement investigators exposed to disturbing media images. Journal of Police and Criminal Psychology, 25, 113-124. doi:10.1007/s11896-010-9066-7 
Powell, M., Cassematis, P., Benson, M., Smallbone, S., \& Wortley, R. (2014). Police officers' strategies for coping with the stress of investigating internet child exploitation. Traumatology: An International Journal, 20(1), 32-42. doi:10.1037/h0099378

Roach, J., Cartwright, A., \& Sharratt, K. (2017). Dealing with the unthinkable: A study of the cognitive and emotional stress of adult and child homicide investigations on police investigators. Journal of Police and Criminal Psychology; the Official Journal of the Society for Police and Criminal Psychology, 32(3), 251-262. doi:10.1007/s11896-016$9218-5$

Rumens, N., \& Broomfield, J. (2012). Gay men in the police: Identity disclosure and management issues. Human Resource Management Journal, 22(3), 283-298.

Sandhu, D. K., Rose, J., Rostill-Brookes, H., \& Thrift, S. (2012). 'It's intense, to an extent': A qualitative study of the emotional challenges faced by staff working on a treatment programme for intellectually disabled sex offenders. Journal of Applied Research in Intellectual Disabilities, 25(4), 308-318.

Severson, M., \& Pettus-Davis, C. (2013). Parole officers' experiences of the symptoms of secondary trauma in the supervision of sex offenders. International Journal of Offender Therapy \& Comparative Criminology, 57(1), 5-24. doi:10.1177/0306624X11422696

Shelby, R., Stoddart, R., \& Taylor, K. (2001), Factors Contributing to Levels of Burnout Among Sex Offender Treatment Providers. Journal of Interpersonal Violence, 16(11), 12051217.

Smith, J. A., Flowers, P., \& Larkin, M. (2009). Interpretative phenomenological analysis: Theory, method and research. London, UK: Sage Publishing. 
Speckens, A., Ehlers, A., Hackmann, A., Ruths, F., \& Clark, D. (2007). Intrusive memories and rumination in patients with post-traumatic stress disorder: A phenomenological comparison, Memory, 15 (3), 249-257, DOI: 10.1080/09658210701256449

Thomas, T. (2016). The police investigation of reports. In Thomas, T. (ed.), Policing sexual offences and sex offenders (pp. 29-41). London, UK: Palgrave Macmillan

Tuckey, M. R., Winwood, P. C., \& Dollard, M. F. (2012). Psychosocial culture and pathways to psychological injury within policing. Police Practice \& Research, 13(3), 224-240. doi:10.1080/15614263.2011.574072

U.S. Department of Justice. (2016). The national strategy for child exploitation prevention and interdiction. Retrieved from https://www.justice.gov/psc/file/842411/download

Wolak, J., \& Mitchell, K. J., (2009). Work exposure to child pornography in ICAC taskforces and affiliates. Retrieved from http://unh.edu/ccrc/pdf/Law\%20Enforcement\%20Work\%20Exposure\%20to\%20CP.pdf

Wolak, J., Liberatore, M., \& Levine, B. N. (2014). Measuring a year of child pornography trafficking by U.S. computers on a peer-to-peer network. Child Abuse and Neglect, 38(2), 347-356. doi:10.1016/j.chiabu.2013.10.018

Wood, H. (2011). The internet and its role in the escalation of sexually compulsive behaviour. Psychoanalytic Psychotherapy, 25(2), 127-142. doi:10.1080/02668734.2011.576492

World Health Organisation. WHO (1992).International Statistical Classification of Diseases and Related Health Problems, 10th Revision (ICD-10). Geneva: WHO 
YOU DON'T SEE THE WORLD THROUGH THE SAME EYES

Wright, R., Powell, M. B., \& Ridge, D. (2006). Child abuse investigation: An in-depth analysis of how police officers perceive and cope with daily work challenges. Policing, 29(3), 498-512. doi:10.1108/13639510610684728 